\title{
CAMINHO DA ENERGIA
}

\author{
Taciane Aparecida Cigognini ${ }^{1}$, Laraine Guialis ${ }^{2}$, \\ Adriana Vanessa Fell Mallmann ${ }^{3}$, Luis Gustavo Fernandes dos Santos ${ }^{4}$, \\ Sonia Elisa Marchi Gonzatti ${ }^{5}$
}

Resumo: Este trabalho foi desenvolvido durante as aulas de Seminário Integrado, em uma escola pública do Vale do Taquari, com estudantes de Ensino Médio. Tendo em vista o avanço das tecnologias e o aumento da demanda por energia elétrica, já que a cada dia os seres humanos tornam-se mais dependentes da utilização dos aparelhos/ equipamentos elétricos, objetivou-se buscar algo diferente para geração de energia sustentável. Na cidade de Fazenda Vilanova, há um viaduto em uma rodovia federal, no qual trafegam muitos veículos diariamente. Por meio de pesquisas descobriuse que o peso e o movimento são capazes de produzir energia elétrica utilizando-se da piezoeletricidade e, esta seria uma possibilidade inovadora para a cidade, e por consequência no país. Este projeto foi apresentado na $5^{a}$ Feira de Ciências UNIVATES, sintetizando as principais etapas da investigação realizada. Para tanto, utilizouse uma maquete feita com peças de lego, LEDs e minipiezoelétricos. Nos testes, os minipiezoelétricos ao sofrerem pressão ou vibração, produziram energia elétrica suficiente para acender os LEDs, corroborando em escala menor o que poderia ser possível de se realizar em escala real.

Palavras-chave: Piezoelétricos. Energia Sustentável. Seminário Integrado.

1 Aluna $3^{\circ}$ Ano, Escola Estadual de Ensino Médio Fazenda Vilanova.

2 Aluna $3^{\circ}$ Ano, Escola Estadual de Ensino Médio Fazenda Vilanova.

3 Mestra em Ensino de Ciências Exatas (Univates). Professora - EEEM Fazenda Vilanova. E-mail: vanessamallmann@universo.univates.br.

4 Mestrando Programa de Pós-graduação Mestrado em Ensino de Ciências Exatas (Univates). Professor IFSul Charqueadas. E-mail: gustavofs@charqueadas.ifsul.edu.br.

5 Doutora em Educação (PUCRS). Professor Univates. E-mail: soniag@univates.br. 


\section{INTRODUÇÃO}

O projeto aqui apresentado emergiu durante as aulas do Seminário Integrado, vinculado ao Ensino Médio de uma escola pública do Vale do Taquari. Durante as aulas, realizaram-se leituras, pesquisas e reflexões embasadas em diferentes artigos relacionados à temática energia sustentável e piezoeletricidade. A partir destes estudos, elaborou-se um projeto de pesquisa e posteriormente uma maquete da proposta, elucidando o desenvolvimento das atividades no decorrer do ano letivo de 2015, posteriormente este trabalho foi apresentado na $5^{\mathrm{a}}$ Feira de Ciências UNIVATES. Este evento traz a temática da pesquisa, fomentando-a e descobrindo novos talentos anualmente, divulgando suas descobertas em diversas áreas do conhecimento. Nesse sentido, pode-se conceber esta Feira como um espaço pedagógico relevante para compartilhar saberes e experiências, o qual valoriza a produção de conhecimentos conectados às demandas e às problemáticas específicas de cada comunidade, mas que ao mesmo tempo se articulam às grandes temáticas socioambientais. Neste evento, $\mathrm{o}$ projeto em questão recebeu o $1^{\circ}$ lugar entre as escolas não pertencentes à cidade de Lajeado - RS.

Objetivou-se neste artigo apresentar um relato de uma atividade desenvolvida, bem como os resultados obtidos durante a pesquisa realizada nas aulas de Seminário Integrado, por estudantes no Ensino Médio Politécnico, em uma escola do Vale do Taquari. Ademais, buscou-se descrever sobre a experiência de participar em um Evento regional e obter o reconhecimento pelo trabalho.

Neste contexto, considera-se que com a evolução da humanidade e o avanço das tecnologias, os seres humanos estão a cada dia com maior dependência dos aparelhos elétricos e tecnológicos, tanto no trabalho, quanto nas residências. Neste contexto, não se pode esquecer que estes ambientes dependem de energia elétrica para funcionar, o que incentiva a busca de fontes alternativas e limpas de produção de energia elétrica que atendam a demanda. Infelizmente, muitos desses meios prejudicam o meio ambiente, por outro lado, refletem alto custo aos consumidores. Assim, nosso trabalho de pesquisa terá ênfase na geração de energia sustentável.

Em Fazenda Vilanova, cidade onde os pesquisadores residem, não há produção de energia elétrica, tanto por ser um município pequeno, quanto por não apresentar rios, que poderiam gerar energia com hidrelétricas. Também, acredita-se que não seria viável gerar energia eólica, pois no município não há grande quantidade de vento diariamente. As placas solares poderiam ser uma das alternativas para gerar energia para o município, mas nossa ideia está voltada para a exploração de energia sustentável, a partir do fluxo contínuo de veículos no viaduto existente no centro desta cidade. Buscando-se algo inovador, neste estudo, encontrou-se que a variação do peso dos veículos e o movimento sobre o viaduto são capazes de produzir energia utilizando a piezoeletricidade. 
Considerando que no município há um viaduto e nele trafegam centenas de carros todos os dias, gerar energia por intermédio do peso dos veículos que passam por esse viaduto, poderia ser uma possibilidade de fonte para produção de energia elétrica sustentável, algo inovador tanto no município, quanto no país.

\section{REFERENCIAL TEÓRICO}

Inicialmente realizaram-se leituras e pesquisas, sobre a temática escolhida, no intuito de embasar-se teoricamente. Neste contexto, identificouse que Energia, em grego, significa trabalho e inicialmente era usado para se referir aos fenômenos explicados, através de termos como "força" e "calórico". Segundo Bucussi (2007), a primeira pessoa a usar o termo energia foi Thomas Young, em 1807. A concepção que ele tinha era que a "energia informa a capacidade de um corpo realizar algum tipo de trabalho mecânico", palavras usadas também por Wilson, em 1968. A partir do século XIX, o termo energia começou a ser usado com mais frequência, porém foi um pouco antes de 1850 que os conceitos de energia protagonizaram uma mudança nos pensamentos científicos na Europa. Esses pensamentos estavam relacionados à outra visão, essa que partia da ideia de diversos fenômenos físicos e químicos, que estruturariam o Princípio de Conservação da Energia.

Conforme estudos realizados por Farias e Sellitto (2011), desde o período paleolítico houve uma preocupação para obter uma forma de luz artificial, já que as pessoas possuíam hábitos diurnos e noturnos. A primeira conquista alcançada nessa direção foi quando o homem conseguiu dominar o fogo, já que ele era utilizado como fonte de luz, calor e proteção. Foi usado também na caça, pois com as tochas, o homem assustava a presa e a encurralava. Foi nessa época também, que o homem aprendeu a cozinhar os alimentos, o que os tornava mais saborosos e saudáveis. Já na Idade Média, o desenvolvimento de áreas como a Matemática e a Engenharia catalisaram o domínio e a transformação das formas de energia disponíveis na natureza. O carvão mineral foi à principal fonte primária de energia do mundo, até ser ultrapassado pelo petróleo.

Conforme Abreu (2010), até o final do século XIX, o estudo de fenômenos elétricos e magnéticos interessava a poucos cientistas. Na época, as casas eram iluminadas por velas, lampiões e lamparinas. A partir de 1800, surgiram na Europa algumas companhias comerciais de iluminação a gás, porém como essa nova tecnologia ameaçava as indústrias de vela, esse tipo de iluminação foi descrito como uma ameaça à saúde, principalmente pelo seu risco explosivo. Por outro lado, esta energia trazia benefícios, como mais energia, por um custo menor e assim essa indústria cresceu rapidamente.

Ainda conforme discorre o autor acima citado, várias descobertas sobre a energia foram feitas. Uma das mais importantes foi realizada pelos cientistas Michael Faraday (1791-1867) e Joseph Henry (1797-1878), que trabalharam em 
épocas diferentes. Faraday construiu uma máquina que gerava tensão elétrica com base em princípios de indução magnética e Henry descobriu o fenômeno da indução eletromagnética, porém tais descobertas foram realizadas quase que ao mesmo tempo, aplicando assim estes conhecimentos em muitas áreas, incluindo eletroímãs e telégrafos. Durante o período de 1840 e 1880, vários profissionais utilizaram o princípio da indução eletromagnética na construção de geradores elétricos. Também nesse período, começou a ser observado que ao afastar dois eletrodos de carbono que estavam conduzindo corrente elétrica, formava-se um brilho intenso.

Abreu (2010) alude ainda que, no final do século XIX, começou a ser feita a comercialização de iluminações a arco voltaico, um tipo de lâmpada que gera luz por meio de um arco elétrico, onde os dispositivos são constituídos por dois eletrodos e separados por um gás como o néon, o árgon, o xénon, o crípton ou o mercúrio no interior de um invólucro. Inicialmente eram usadas apenas em residências, mas que com o passar do tempo, foi usada em ambientes externos, como por exemplo, na iluminação pública. Com a comercialização destas lâmpadas, foram criados geradores elétricos melhores e mais eficientes. Com isso, idealizou-se que se uma lâmpada elétrica incandescente fosse criada, estaria disponível uma boa fonte de energia.

Ainda, seguindo a narrativa histórica do autor supracitado, em 1875, Thomas Edison (1847-1931) fundou o primeiro centro de pesquisas fora de uma universidade, onde trabalhou em várias pesquisas na área da eletricidade, entre elas, o desenvolvimento de uma lâmpada elétrica incandescente. Após quatro anos de muitas experiências sem sucesso, conseguiu criar um bulbo com vácuo contendo um fio de algodão carbonizado e energizado, mas a lâmpada queimou após 44 horas de funcionamento. Essa lâmpada foi aprimorada e em 1882, nos EUA, foi instalado o primeiro sistema de vendas de energia elétrica. Assim, deu-se o início do que se tornou uma das maiores indústrias do mundo. Já em 1886, George Westhinghouse, pela primeira vez, transmitiu energia elétrica em corrente alternada. O uso dessas correntes e dos sistemas polifásicos desenvolvidos por Nikola Tesla, juntamente com o eficiente transformador de Willian Stanley, proporcionaram a transmissão a grandes distâncias e inicia o uso doméstico da energia elétrica.

Uma das primeiras energias sustentáveis foi à energia hidrelétrica. Na página SEED Ciências, disponível em <http://www.planetseed.com>, encontramos que as rodas d'água já eram usadas pelos gregos e romanos desde a Antiguidade para movimentar maquinários. No século XVII moinhos de água já eram usados pelas fábricas na Inglaterra, porém foi só em 1882 que foi aberta a primeira usina hidrelétrica, nos Estados Unidos. A partir desse momento, as fontes de energia foram se aperfeiçoando e novas fontes de energias sustentáveis foram instituídas.

Segundo a página online Itaipú Binacional, por volta de 1960, Brasil e Paraguai iniciaram em parceria, o projeto que se tornaria uma das maiores 
hidrelétricas do mundo. Atualmente, a Itaipu Binacional é líder mundial em produção de energia limpa e renovável. Em 2014, operando com 20 turbinas, a Itaipu produziu cerca de 87,8 milhões de Megawatts/hora (MWh), porém seu recorde foi em 2013, quando produziu mais de 98,6 milhões de MWh.

Conforme o site oficial da Usina, disponível em <www.itaipu.gov.br>, sua potência fornece cerca de $17 \%$ da energia consumida no Brasil e $75 \%$ no Paraguai. Essa usina é um marco para o setor elétrico tanto do Brasil, quanto do Paraguai, já que quando foi construída, nos dois países a energia hidrelétrica não era um fator muito forte. Além disso, no ano em que o Tratado de Itaipu foi assinado, houve uma crise mundial pelo preço do petróleo, pois até então, era a principal fonte geradora de energia. A construção da Itaipu foi uma forma de explorar novas fontes de energia renovável e garantir um enorme desenvolvimento para os dois países.

Segundo Brain (2014), independente de qual fonte está sendo utilizada para a produção de energia, há três fatores que não mudam: a fonte de eletricidade com dois pólos, sendo um positivo e o outro negativo, a fonte vai deslocar os elétrons para fora do terminal negativo com certa diferença de potencial e os elétrons necessitam de um condutor, normalmente um fio de cobre. Quando existe um caminho que vai do terminal negativo para o positivo, existe o chamado circuito, onde os elétrons percorrem por um condutor. Qualquer dispositivo que precise de eletricidade para funcionar pode ser conectado no meio do circuito e a fonte de eletricidade vai fornecer energia para o dispositivo e este irá fazer o seu trabalho. Se o dispositivo for uma lâmpada, por exemplo, ela irá gerar a luz.

Como já citado anteriormente, o tema energia renovável vem ganhando espaço nos meios científicos, considerando que atualmente com o avanço das tecnologias, energia é fundamental para o ser humano viver. Apesar de o tema ser atual, muitas pessoas desconhecem sobre o que é energia renovável. Segundo Pacheco (2006), “as energias renováveis são provenientes de ciclos naturais de conversão da radiação solar, fonte primária de quase toda energia disponível na Terra e, por isso, são praticamente inesgotáveis e não alteram o balanço térmico do planeta e se configuram como um conjunto de fontes de energia que podem ser chamadas de não-convencionais, ou seja, aquelas não baseadas nos combustíveis fósseis e grandes hidroelétricas".

Energia renovável é um tema importante, não apenas por possibilitar ligar uma televisão, por exemplo, mas também porque abrange várias necessidades, como as ambientais, econômicas e de desenvolvimento. Criar energia por meio de um meio que não prejudica o meio ambiente é fundamental nos dias atuais, já que tantos problemas ambientais estão emergindo.

Novas tecnologias sustentáveis estão surgindo a cada dia e alguns países estão se destacando, principalmente no uso de energias hidrelétricas. Em 2014, a The Global Cleantech Innovation Index, divulgou uma lista com os países que lideram a chamada Revolução Verde, disponível em <http://www.neosolar. 
com.br>. Além da eficiência energética, foram analisados também fatores como fontes renováveis, tratamento de lixo e sistemas de reuso de água. Abaixo, sucintamente, serão destacados os países da lista e suas fontes de energia.

Israel possui pelo menos $90 \%$ das residências que usam energia solar para aquecer a água. Na Finlândia, mais da metade das novas indústrias do país trabalham buscando soluções na eficiência energética. Os EUA não possuem forte consumo de energia renovável, porém somam mais de US\$5 bilhões em investimentos em tecnologias sustentáveis. O governo da Suécia oferece altos financiamentos para pesquisas e desenvolvimento de tecnologias sustentáveis. A Dinamarca vem se destacando pela capacidade de apoiar empresas que desenvolvem tecnologias sustentáveis, até que estas se tornem lucrativas, beneficiem a economia do país e o meio ambiente. O Reino Unido se destaca na produção de energia eólica, com cerca de 3\% da energia eólica produzida no mundo. O Canadá, estimula e investe nas novas tecnologias, como por exemplo, na prática de captura e armazenamento de carbono, além de possui a nona maior capacidade de energia eólica instalada no mundo. $\mathrm{Na}$ Suíça, as tecnologias sustentáveis correspondem a 3,5\% do PIB do país e empregam aproximadamente $4,5 \%$ da população. Na Alemanha, se produz aproximadamente $35 \%$ da energia solar do planeta. Além disso, investe em energia eólica, com $11 \%$ da capacidade instalada mundialmente. Na Irlanda, são investidos aproximadamente 2,5 bilhões de euros em novas soluções energéticas sustentáveis.

Nesta lista, o Brasil está classificado em $25^{\circ}$ lugar e o transporte mais utilizado para locomoção das pessoas é o carro. Neste sentido, o tráfego de veículos é uma possibilidade para produção de energia sustentável em nosso país. Como as pessoas estão cada vez mais dependentes de energia elétrica e os estudos apontam que o potencial energético aumenta, é relevante (re)pensar métodos de produção de energia renovável.

Buscou-se pesquisar também sobre os métodos já existentes e projetos que estão ainda em fase de testes, que geram energia elétrica em pontes ou estradas. Barbosa (2014), apresenta o caso de um casal americano que criou um projeto denominado Solar Roasways, que substitui o asfalto tradicional nas estradas por painéis fotovoltaicos, ou seja, painéis que geram energia através do calor do Sol. As células fotovoltaicas produzem a eletricidade e são protegidas por um vidro, semelhante ao asfalto, durável, sem brilho e antiderrapante, na qual a parte superior é apoiada por borracha e concreto na parte inferior. Cada placa fotovoltaica está ligada a um sistema central, onde a energia é gerada e transferida para a rede. Para provar que o sistema é eficiente e forte o suficiente para aguentar veículos pesados, caso fosse instalado em uma rodovia, o casal testou o sistema em um estacionamento privado e passou com um trator por cima, obtendo resultados positivos. Agora, o objetivo deste casal é aperfeiçoar o projeto e se possível, instalar em uma rodovia. 
Outra possibilidade são os geradores eletrocinéticos que aproveitam as irregularidades da pista, como por exemplo, buracos e lombadas. Se esse método for instalado em uma lombada, por exemplo, ao passar por cima dela, o carro fará uma pressão. A velocidade e o peso do veículo determinarão a quantidade de pressão e consequentemente, a quantidade de energia a ser gerada.

São utilizados também geradores Eólicos, proposto por três designers italianos, no projeto Solar Wind Bridge. A proposta deles é gerar energia elétrica instalando turbinas de vento entre os pilares de uma ponte, o que geraria, conforme informa a empresa responsável pelos testes, aproximadamente 36 milhões de $\mathrm{KWh}$, além de revestir o asfalto com placas solares, o que iria gerar aproximadamente 11 milhões de KWh por ano. Neste sentido, pesquisas dos designers revelam que essa ponte poderia abastecer aproximadamente 15 mil casas. Além da geração de energia, a ponte proporcionaria os chamados Passeios Verdes, ou seja, em uma determinada área da ponte, os carros que trafegam poderiam estacionar e admirar a vista.

Os geradores piezoelétricos, foco deste trabalho, permitem que ao pisarmos no chão, ou no caso desta proposta, passarmos com veículos sobre o asfalto, através do peso e da velocidade, cria-se energia. Segundo Vieira (2013) esta é uma forma bastante eficiente para transformar energia mecânica em energia elétrica e que já é utilizada em várias partes do mundo. Neste sentido,

O efeito piezoelétrico (do grego, "eletricidade por pressão" foi descoberto pelo pelos irmãos Pierre e Jacques Currie em 1880. Tratase da propriedade que certos cristais possuem de liberar elétrons proporcionalmente em resposta à pressão mecânica. Ocorre porque cristais piezoelétricos possuem átomos eletricamente neutros em seu interior que não estão simetricamente arranjados, suas cargas elétricas são perfeitamente balanceadas, uma carga positiva cancela uma carga negativa na sua proximidade, ou seja, os momentos de dipolos elétricos se cancelam. Assim, se uma pressão mecânica for realizada em um cristal piezoelétrico, ocorrerá uma deformação na sua estrutura, fazendo com que alguns átomos fiquem mais próximos e outros mais distantes (ANTUNES; SOUSA; SCHERTEL, 2014, p. 2).

Apesar de ser pouco conhecida, a piezoeletricidade já existe há bastante tempo. No século XIX, Charles Coulomb e Henri Becquerel descobriram que determinados materiais, ao serem aquecidos, possuíam comportamentos elétricos, passando a ser chamados de piroeletricidade. No mesmo século, os irmãos Pierre e Jacques Currie descobriram materiais parecidos, mas que geravam tensão elétrica quando pressionados, os piezoelétricos.

Muitas pessoas desconhecem, mas os piezoelétricos são encontrados em materiais como microfone, acendedor de fogões, lanternas, balanças eletrônicas, 
brinquedos, cartões musicais e alarmes. Em todos esses equipamentos, a energia mecânica é convertida em energia elétrica, porém, os piezoelétricos também são encontrados em outros locais, como por exemplo, na pista de dança da casa noturna Surya, localizada em Londres, conforme está representado na Figura 1 que segue.

Figura 1: Ilustração da casa noturna

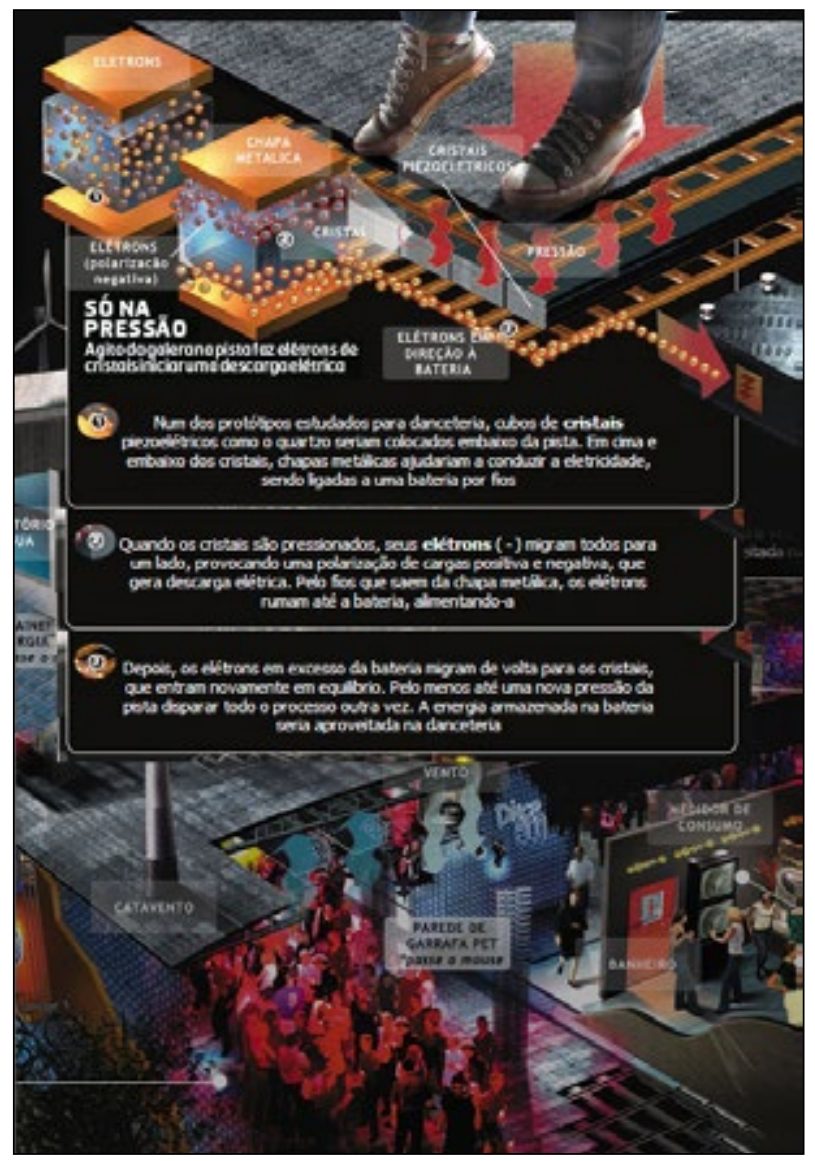

Fonte: <www.duniverso.com.br/surya-em-londres-o-primeiro-night-clube-ecologico-do-planeta $>$.

Conforme as pessoas se movimentam na pista dançando, o chão, que é revestido de piezoelétricos, sofre grande pressão. A energia é gerada, abastecendo o som e a luz da boate. Quando o movimento no local não é muito grande, a luz não acaba, pois além da piezoeletricidade, a boate conta também com um sistema de baterias, painéis solares e uma turbina eólica. Dessa forma, a energia gerada pode até ser compartilhada com os vizinhos. Segundo os criadores desse sistema, a pista de dança consegue produzir cerca de $60 \%$ de toda a energia. 
A primeira cidade do mundo a testar essa tecnologia nas calçadas das ruas, foi Toulouse, na França. Segundo as autoridades locais, com oito placas piezoelétricas instaladas, de dimensões não especificadas, é possível produzir cerca de 480 watts de eletricidade. Em Gloucester, na Inglaterra um supermercado instalou placas piezoelétricas em seu estacionamento. Com isso, foi possível produzir $30 \mathrm{kWh}$. Em Tóquio, placas piezoelétricas foram instaladas em uma estação de metrô. A energia gerada alimenta letreiros luminosos e catracas eletrônicas. Já a empresa israelense, Innowattech faz testes com piezoelétricos em estradas, trilhos de trem, pistas de aeroportos e estações de metrô. Segundo as pesquisas da empresa, com 20 carros passando por uma rodovia por minuto, é possível gerar $200 \mathrm{kWh}$. Porém, segundo Antunes, Sousa e Schertel (2014)

A utilização do piso ainda enfrenta algumas dificuldades e ainda é necessário aprimoramentos, por exemplo, um dos desafios é o armazenamento de energia que tem sido realizado por supercapacitores, pesquisa-se formas de armazenamento mais baratas. A durabilidade da placa também é um problema que vem sendo enfrentado, já que para Universidade Federal do Rio Grande doSul-UFRGSEscola de Engenharia EEN99004-Projeto em Energia III Engenharia de Energia 2014/2 ser instalado, por exemplo, em uma rodovia, precisa ser capaz de se deformar e voltar ao seu estado inicial após cessado o estímulo, resistir aos agentes externos, ao seu uso constante e não deixar de produzir o efeito piezoelétrico.

Neste sentido, embasados por estudos teóricos e medições em escala menor, mais especificamente, nos testes realizados com auxílio da maquete construída pelas estudantes, consideramos que o fluxo intenso de veículos na BR 386, em Fazenda Vilanova, mais especificamente sobre o viaduto, pode ser viável para produção de energia elétrica, utilizando piezoeletricidade. Para tanto destaca-se a necessidade de aprofundamento nos estudos, visando a custos, matérias e possibilidade de se adaptar na pista, dificuldades encontradas também por outros pesquisadores.

\section{METODOLOGIA E RESULTADOS}

Pesquisou-se sobre os assuntos relevantes para o desenvolvimento deste projeto em livros, artigos científicos e na internet. Buscou-se conhecer como surgiu a energia elétrica, seus avanços e como ela foi e esta sendo produzida, a energia sustentável, em especial no foco deste estudo a pizoeletricidade. Procurou-se obter exemplos de como funcionam as pontes sustentáveis que já existem em outros países, com ênfase naquelas que produzem energia elétrica com o peso e o movimento dos veículos e outros temas relevantes que emergiram durante a pesquisa. A elaboração do projeto desta pesquisa se deu em 2014, durante o primeiro ano das estudantes, no Ensino Médio Politécnico. 
Em continuidade à proposta deste trabalho de pesquisa, no ano de 2015, aprimorou-se os estudos teóricos, testes foram realizados e fez-se a representação do trabalho em uma maquete (FIGURA 2), acerca da possibilidade de produção de energia elétrica sustentável, no viaduto da rodovia federal da cidade. Para a construção da maquete, foram utilizados materiais de lego educacional e alguns conceitos desta metodologia, principalmente em respeito à estrutura.

Figura 2- Maquete apresentada na Feira de Ciências UNIVATES

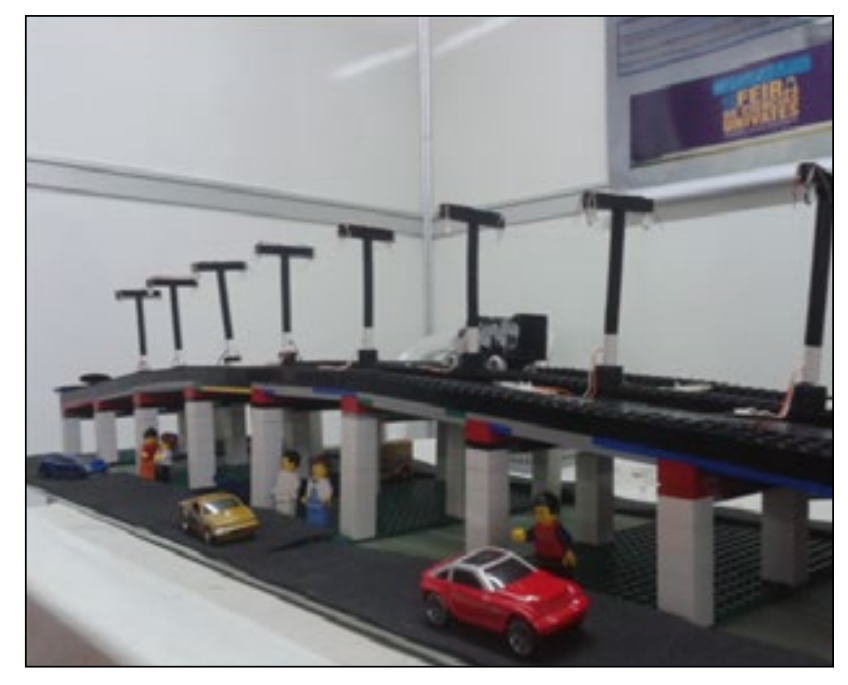

Fonte: Registro de imagem da maquete, realizada pelos autores.

Nos testes realizados com minipiezoelétricos individuais, de $35 \mathrm{~mm}$ (FIGURA 3), percebe-se que ao sofrer uma pressão ou vibração, o Led de 3 volt nele ligado acende (FIGURA 4), demonstrando assim, que a proposta, em escala menor obteve resultados favoráveis. As instalações elétricas foram realizadas com a utilização de solda de estanho e fios de cobre. Para a realização da solda, contou-se com a colaboração de um professor do IFSul, de Charqueadas. A visita ao Instituto Federal foi uma das saídas de campo, integrante desta pesquisa, que se constitui em um momento importante de aprendizagem e o reconhecimento de um espaço diferente de ensino. 
Figura 3 - Leds utilizados (35mm)

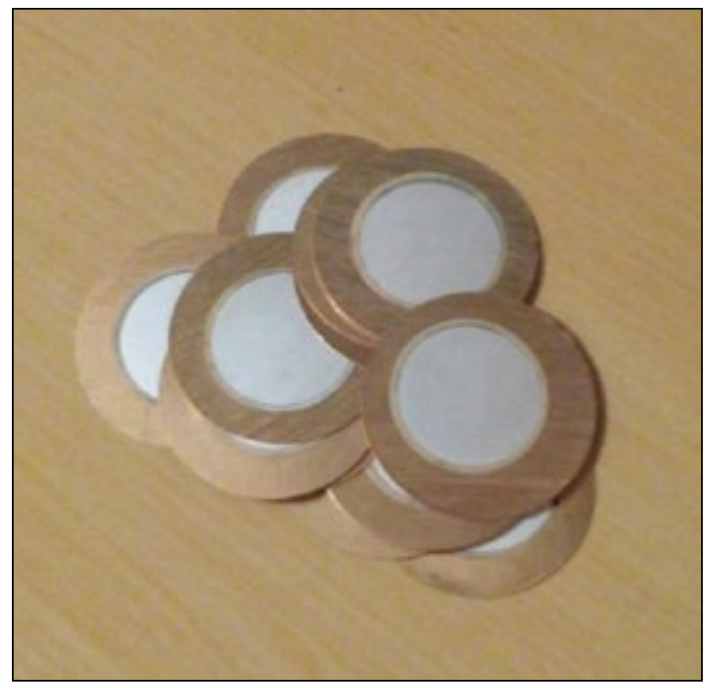

Fonte: Registro de imagem realizado pelos autores.

Figura 4 - Testes com o material

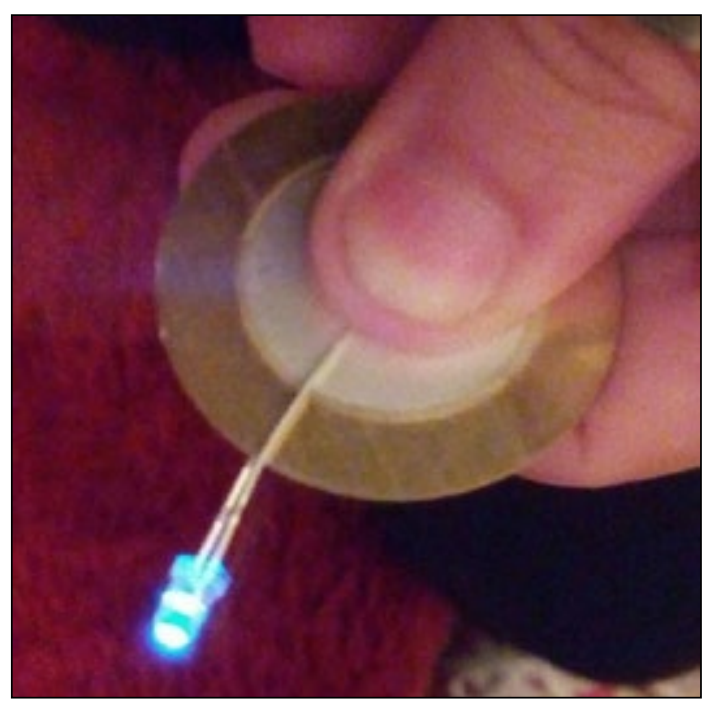

Fonte: Registro de imagem realizado pelos autores.

Posteriormente, o projeto de pesquisa desenvolvido foi apresentado na $5^{\text {a }}$ Feira de Ciências Univates, descobrindo talentos para a pesquisa, no ano de 2015. A oportunidade foi ímpar para as estudantes e a professora, que tiveram a oportunidade, pela primeira vez, de apresentar resultados de um 
estudo, realizado em uma escola pública e ser reconhecido. O evento culminou em troca de experiência, com outros estudantes, professores e pesquisadores, além de ampliar a visão de mundo, ultrapassando as portas da sala de aula. Sem dúvidas, receber elogios, incentivo do público e Menção Honrosa, da Universidade, motivou e marcou a vida escolar e acadêmica dos envolvidos. Ademais, o trabalho obteve destaque em um jornal da região, por mérito ao primeiro lugar entre as escolas não pertencentes a Lajeado.

Almeja-se pela possibilidade de futuramente sugerir a adesão da proposta para o Município de Fazenda Vilanova, a distribuição de energia elétrica renovável, produzida utilizando recursos disponíveis no local, visando mínimos prejuízos ao meio ambiente. Na cidade, já existe um viaduto, o que facilita a proposta da implementação do projeto. Esta ideia vislumbra benefícios para a cidade, como econômica, financeira e de segurança pública, a partir da iluminação pública, além de ser uma tecnologia inovadora, uma nova forma de produção de energia renovável, tanto na região, quanto no próprio país.

\section{CONSIDERAÇÕES FINAIS}

Muitos questionamentos ainda emergem deste trabalho, o que instiga os autores a busca de mais informações, como investigar a quantidade de energia possível de ser gerada, em $\mathrm{kWh}$, por meio deste método, sobre o fluxo de veículos no viaduto local, os custos de instalação e as possíveis implicações para a implementação da proposta no município.

Descobriu-se que individualmente os minipiezoelétricos podem gerar energia a cada vibração sofrida, com apenas toques com as mãos. Levando isso em consideração e as leituras realizadas, ponderamos que a proposta de geração de energia sustentável utilizando a piezoeletricidade no viaduto de Fazenda Vilanova, adaptada ao asfalto, seria possível. Neste contexto, em escala maior, devido à vibração sofrida pela pressão de um carro ao passar na via, pode-se deduzir que a produção de energia, atingirá maior quantidade, podendo ser armazenada em baterias e distribuída.

Quanto ao envolvimento e a aprendizagem das estudantes, pode-se dizer que demandou maior autonomia e dedicação. Tanto a parte escrita e as leituras, quanto a construção da maquete e seus testes exigiu empenho e atividades extraclasse. A participação na Feira de Ciências foi uma oportunidade diferente e desafiadora, que proporcionou novos conhecimentos. Para a professora, a experiência de orientar um trabalho de pesquisa, rompendo com as práticas mais comuns na escola, o quadro e o giz da sala de aula. Estudar e descobrir dados novos, vibrando com as conquistas e evolução do trabalho e a formação das alunas como cidadãs, com consciência ambiental.

Este trabalho possibilitou ampliar conhecimentos sobre a temática Energia Sustentável e Piezoeletricidade. Ademais, demandou estudo e pesquisa, o que favoreceu uma metodologia diferente de aprender, associando 
um estudo de um contexto real, com testes na maquete, embasado por lentes teóricas. A participação em um evento científico também demandou novas habilidades, como desenvoltura na oratória e postura acadêmica. Espera-se ter apresentado os resultados obtidos na pesquisa e o quanto à experiência vivenciada pelos envolvidos foi importante.

\section{REFERÊNCIAS}

ANTUNES E. de G.; SOUSA M. N. de; SCHERTEL M. N. da C. Piso que transforma energia mecânica em eletricidade. EEN99004 - Projeto em Energia III Engenharia de Energia 2014. Universidade Federal do Rio Grande do Sul - UFRGS.

BORBA, Maria Cristina Vidal; GASPAR Neide Ferreira (Tradução): Um futuro com energia sustentável: Iluminando o caminho. [São Paulo]: FAPESP; [Amsterdam] InterAcademyCouncil; [Rio de Janeiro]: Academia Brasileira de Ciências, 2010.300 p: il.; $24 \mathrm{~cm}$. Disponível em: <http://www.fapesp.br/publicacoes/energia.pdf >. Acesso em: 29 abr. 2015.

BUCUSSI, Alessandro A.: Introdução ao Conceito de Energia. Porto Alegre: UFRGS, Instituto de Física, Programa de Pós-Graduação em Ensino de Física, 2007. Disponível em: <http://www.if.ufrgs.br/tapf/v17n3_Bucussi.pdf>. Acesso em: 15 maio 2015.

CIÊNCIA E DIVERSÃO: Disponível em: <http:/ / parquedaciencia.blogspot.com. br/2013/08/a-piezoeletricidade-no-cotidiano.html>. Acesso em: 13 nov. 2014.

COMO TUDO FUNCIONA: Disponível em: <http://ciencia.hsw.uol.com.br/ eletricidade.htm>. Acesso em: 01 abr. 2015.

ENERGIAS RENOVÁVEIS: BREVES CONCEITOS. Disponível em <http:/ /ieham. org $/ \mathrm{html} /$ docs/Conceitos_Energias_renov\%C3\%A1veis.pdf $>$. Acesso em: 23 nov. 2016.

EUMED.NET: Disponível em: <http:/ / www.eumed.net/libros-gratis/2010c/723/ RESUMO \%20DA\%20HISTORIA\%20DA\%20INDUSTRIA\%20DA\%20ENERGIA \%20 ELETRICA.htm>. Acesso em: 15 abr. 2015.

FARIAS, Leonel Marques; SELLITTO, Miguel Afonso: Uso da energia ao longo da história: evolução e perspectivas futuras. Revista Liberato, Novo Hamburgo, v. 12, n. 17, p. 01-106, jan./jun. 2011. Disponível em: <http://www.liberato.com.br/sites/ default/files/arquivos/Revista_SIER/v.\%2012,\%20n.\%2017\%20\%282011\%29/1.\%20 Uso $\% 20 \mathrm{da} \% 20$ energia $\% 20 \mathrm{ao} \% 20$ longo $\% 20 \mathrm{da} \% 20$ hist $\%$ F3ria.pdf $>$. Acesso em: 29 abr. 2015.

INSTITUTO ECO AÇÃO. Disponível em: <http:/ /institutoecoacao.blogspot.com. br/2013/10/ponte-que-produz-energia-renovavel.html>. Acesso em: 01 jul. 2015.

ISTO É. Disponível em: <http:/ / www.istoe.com.br/reportagens/73214_ ENERGIA+LIMPA+SOB+NOSSOS+PES>. Acesso em: 13 nov. 2014. 
ITAIPU BINACIONAL. Disponível em: <http:/ / www.itaipu.gov.br/nossa-historia> Acesso em: 10 abr. 2015.

LAMARÃO, Tadeu de Niemeyer: A Energia elétrica e o parque industrial Carioca (1880-1920). Simposio Internacional Globalización y construcción de redes técnicas urbanas em América y Europa, 1890-1930. Brazilian Traction y otros conglomerados financeiros y técnicos. Universidad de Barcelona, Facultad de Geografia e Historia, 2326 de enero 2012. Disponível em:<http:/ / www.ub.edu/geocrit/Simposio/cLamarao_ Aenergia.pdf $>$. Acesso em: 29 abr. 2015.

NEOSOLAR ENERGIA. Disponível em: <http:/ / www.neosolar.com.br/blog/ conheca-os-10-paises-que-mais-usam-energia-limpa/> . Acesso em: 20 maio 2015.

NOVA ELETRÔNICA: Disponível em: <http://blog.novaeletronica.com.br/usandopastilha-piezoeletrica-como-fonte-de-energia-alternativa/>. Acesso em: 14 maio 2015.

O DIA EM QUE AS ESTRADAS VÃO APROVEITAR A ENERGIA SOLAR ESTÁ CHEGANDO: Disponível em: <http:/ / www.tecnisys.com.br/noticias/2015/o-diaem-que-as-estradas-vao-aproveitar-a-energia-solar-esta-chegando $>$. Acesso em: 26 jun. 2015.

PLANETA SUSTENTÁVEL: Disponível em: <http:/ / planetasustentavel.abril.com.br/ noticia/energia/conteudo_345379.shtml>. Acesso em: 14 maio 2015.

REVISTA GALILEU: Disponível em: <http:/ / revistagalileu.globo.com/Revista / Common/0,EMI270836-17770,00-APARELHO+USA+RESPIRACAO+HUMANA+PA RA+GERAR+ENERGIA.html>. Acesso em: 14 maio 2015. 